
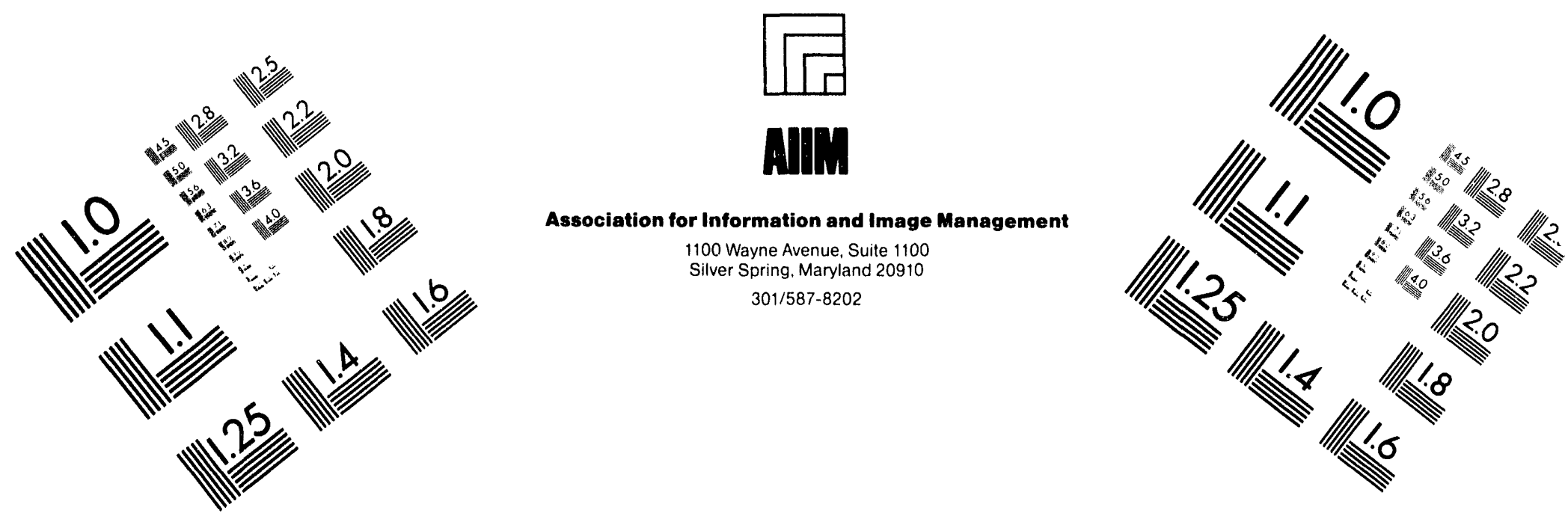

\title{
Centimeter
}

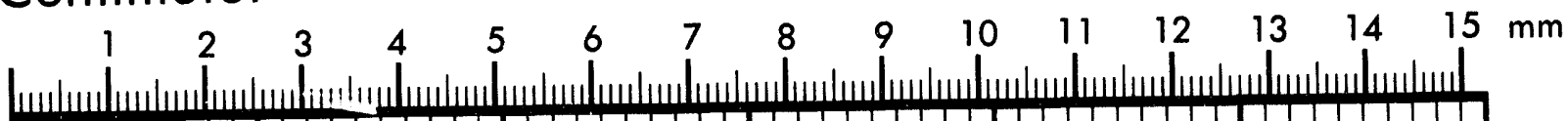

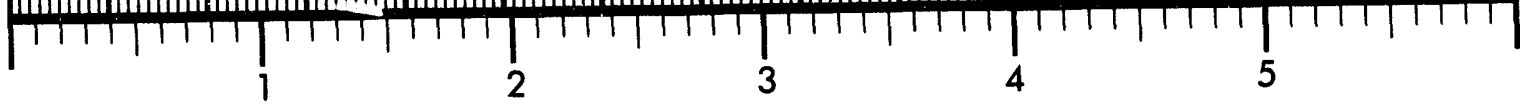
Inches

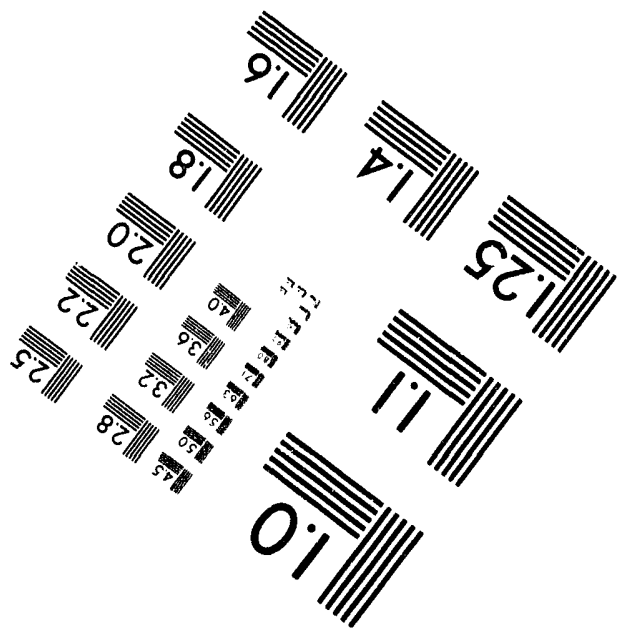

MANUFACTURED TO AIIM STANCARDS BY APPLIED IMAGE. INC.

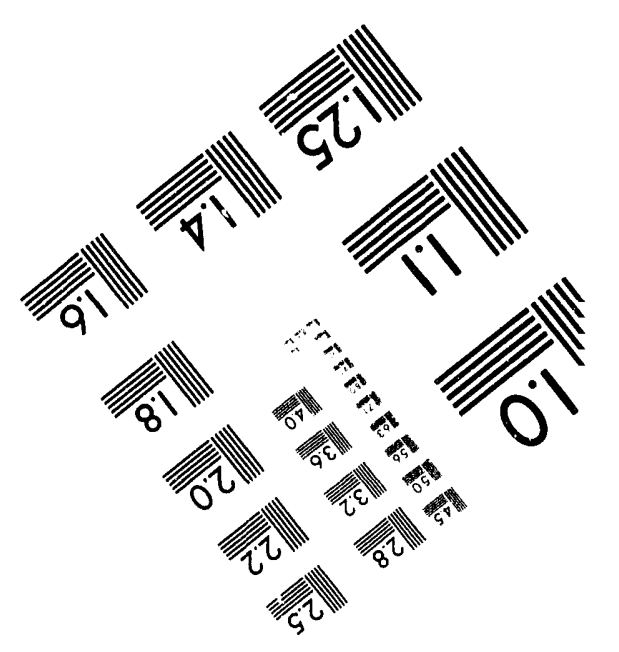



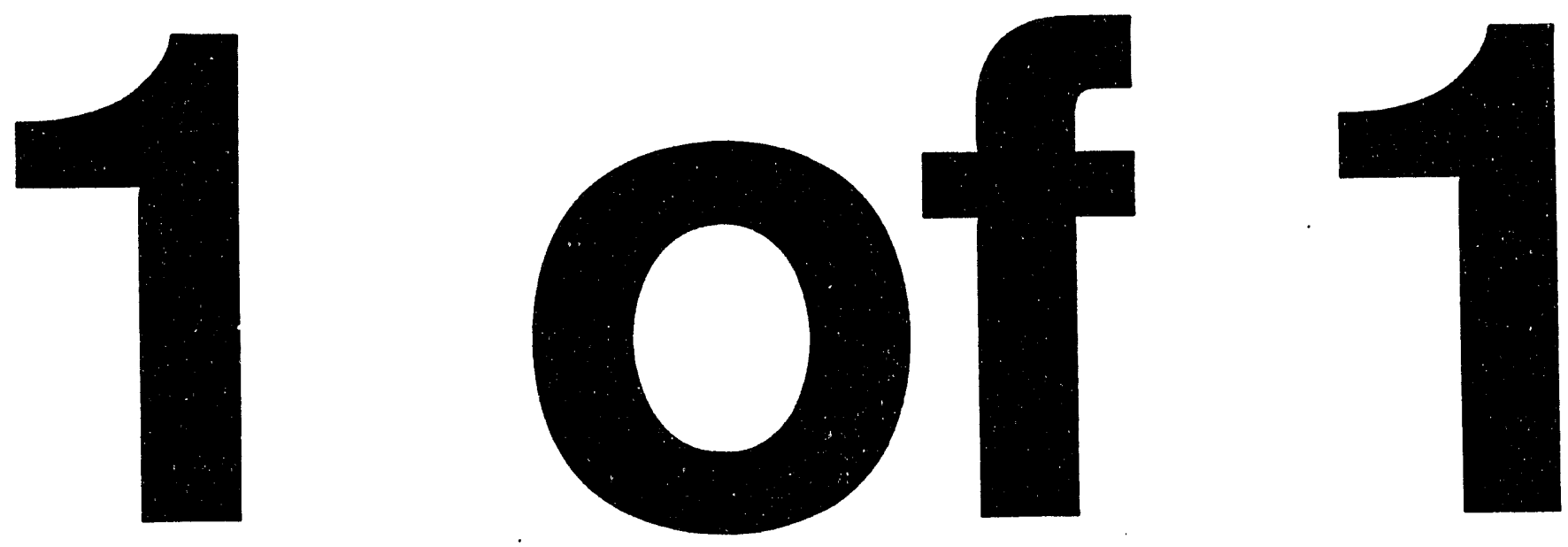
WHC-EP-0785

UC-2070

\section{Raman Spectroscopy Peer Review Report}

W. D. Winkelman

S. J. Eberlein

Date Published

September 1994

Prepared for the U.S. Department of Energy Office of Environmental Restoration and Waste Management

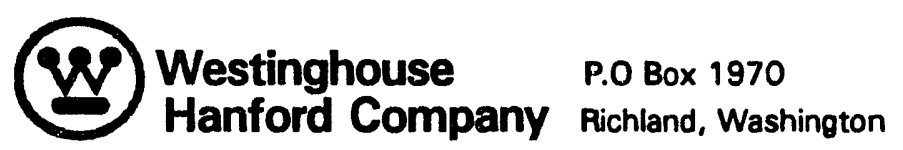

Hanford Operations and Engineering Contrector for the

U.S. Department of Energy under Contract DE-AC06-87RL10930 


\section{RELEASE AUTHORIZATION}

Document

Number:

Document Title:

Release Date:

August 22, 1994

This document was reviewed following the procedures described in WHC-CM-3-4 and is:

APPROVED FOR PUBLIC RELEASE

WHC Information Relesse Administration Specialist:

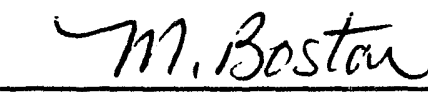

M. N. Boston

(Signature)
WHC-EP-0785

Raman Spectroscopy Peer Review Report

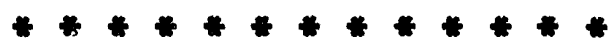

$\frac{8 / 22 / 94}{\text { (Date) }}$




\section{RAMAN SPECTROSCOPY PEER REVIEW REPORT}

\section{Executive Summary}

A review of the Hanford Raman Spectroscopy Program for the characterization and screening of tank waste material was held in Richland on March 23 and 24, 1994. Four of the leading Raman spectroscopists from the United States were present for this review. They are as follows:

- Dr. Bruce Chase, E.I. DuPont Central Research and Development

- Dr. William Fateley, Chemistry Department, Kansas State University

- Dr. Richard McCreery, Ohio State University

- Dr. Shiv Sharma, Hawaii Institute of Geophysics, University of Hawai i.

A team of principal investigators and researchers from Lawrence Livermore National Laboratory, Savannah River Technical Center, Florida State University, the Naval Research Laboratory, and Westinghouse Hanford Company made presentations that covered both technical and programmatic aspects of the Hanford Site Raman work. After these presentations and discussions, the review panel met in a closed session to formalize a list of findings. The reviewers agreed that Raman spectroscopy is an excellent method to attack the tank waste characterization and screening problems that were presented. They agreed that there was a good chance that the method would be successful as presently envisioned.

The reviewers provided the following primary recommendations.

- Evaluate a laser with wavelength in the near infrared (e.g., 780 nanometers [nm]). This will provide better signal transmission over distances, less radiation induced attenuation, and less susceptibility to fluorescence.

- Provide optical filters at or near the sampling end of the fiber-optic probe. This will improve the signal and reduce the dependency on software signal processing.

- Develop and implement a strategy for frequent calibration of the system. This will reduce the stringency of requirements for system stability.

- Do not try to further increase Raman resolution at the expense of wavelength range.

- Clearly identify and differentiate between requirements for providing a short-term operational system and requirements for optimizing a system for long-term field use.

- Determine the best optical configuration, whic may include reduced fiber-optic diameter and/or short focal. 'ngth and low F-number spectrographs.

These recommendations will be incorporated into the program. 
1.0 INTRODUCTION . . . . . . . . . . . . . . . . . . . . 1

1.1 BACKGROUND ........................ 1

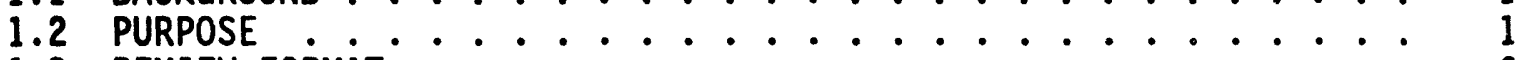

1.3 REVIEW FORMAT ...................... . . . 2

2.0 REYIEW PANEL FINDINGS ...................... 2

2.1 PRIMARY CONCLUSIONS . . . . . . . . . . . . . . . 2

2.2 SYSTEM DESIGN CONSIDERATIONS . . . . . . . . . . . . . . . . . 3

2.2.1 Choice of Laser Wavelength . . . . . . . . . . . 3

2.2.2 Remote Versus Local Filtering ............ . 4

2.2.3 Raman Shift Range and Resolution ........... 5

2.2.4 Time Frame Until Operational Use ........... 5

2.2.5 Frequency and Ease of Calibration ......... 6

2.2.6 Optical Configuration ............ . 6

2.3 ISSUES .. . . . . . . . . . . . . . . . . 8

2.3.1 High Technical Risk Areas ............ 8

2.3.2 Integration Times ............... 8

2.3.3 Operator Training ............... 9

2.3.4 Hardware Versus Software Corrections ......... 9

2.3.5 Detector Noise Sources ............... 9

2.3.6 Software Development Strategy ........... 9

2.3.7 Data Analysis and Chemometrics........... 9

2.3.8 Quantitative Versus Qualitative Results ....... 10

3.0 CONCLUSION . . . . . . . . . . . . . . 10

APPENDIX A: AGENDA AND LETTERS OF APPROVAL . . . . . . . . . A A-1

LIST OF FIGURES

1. Optical Configuration. .................... 7 
WHC-EP-0785

\section{LIST OF TERMS}

CCD charge-coupled device

DOE U.S. Department of Energy

IR infrared

$\mathrm{nm} \quad$ nanometer

UST underground storage tank 
WHC-EP-0785

RANAN SPECTROSCOPY PEER REVIEW REPORT

\subsection{INTRODUCTION}

\subsection{BACKGROUND}

The Hanford Site in eastern Washington includes 177 underground storage tanks (UST), which contain waste materials produced during the production of nuclear fuels. The materials in the tanks must be characterized to support the retrieval, processing, and final disposition of the waste.

Characterization is currently performed by removing waste samples for analyses in a hot cell or laboratory. Subsamples are then removed for further analyses by inspection of the hot cell operators. This inspection is visual and subjective when viewing the samples through the hot cell window. Unknown homogeneity of the sample and desired tank stratification information are two primary problems being targeted by the use of Raman spectroscopy. Screening (assessing relative concentrations of molecular species of interest) of the tank cores along the vertical axis will provide this information. In addition, knowledge of whether a chemical species exists above a threshold value is required information to determine if further analysis should be performed.

Characterization may eventually include in situ analysis of the waste.

The U.S. Department of Energy (DOE), in a multisite program, has been pursuing the use of Raman spectroscopy to support the molecular screening and characterization of UST waste.

\subsection{PURPOSE}

The Raman spectroscopy program, addressing characterization and screening of Hanford Site UST wastes, has advanced to the point of providing significant results on how the Raman technology may be applied to the problem. The purpose of this Peer Review is to obtain, from unbiased experts, a critical review of the methods, equipment, and application of Raman spectroscopy for tank waste material screening and characterization. Four recognized experts in the area of Raman spectroscopy were asked to review technical and programmatic aspects of the development and implementation of Raman spectroscopy, including hardware, software, methodology, and program plan. The programmatic issues were limited to development phases, and the primary issues addressed were technical. The reviewers were asked to identify issues and needs, make recommendations, and indicate if each area is being treated correctly. This Peer Review will provide guidance on how to proceed with the Raman program to ensure successful application of Raman to the UST problems. 


\subsection{REVIEW FORMAT}

The first day of the Peer Review consisted of formal presentations by a team of principal investigators and researchers from Westinghouse Hanford Company, Savannah River Technical Center, Florida State University, the Naval Research Laboratory, and Lawrence Livermore National Laboratory who are responsible for the technical and programmatic aspects of the Hanford Site Raman program. The agenda is given in Appendix $A$.

The reviewers were given an opportunity to ask questions of the presenters and support personnel. On the second day of the review, the peer reviewers met in a closed session with a facilitator and recorder. Issues that had been identified on the first day were discussed and required actions were identified. Each reviewer had an opportunity to present questions, concerns, and findings from the first day. The discussions were summarized and converted into an early draft of this report. All reviewers revised the report before publication in its current form. The peer review panel consisted of Dr. Bruce Chase, E. I. DuPont Central Research and Development; Dr. William Fateley, Kansas State University; Dr. Richard McCreery, Ohio State University; and Dr. Shiv Sharma, University of Hawaii.

\subsection{REVIEW PANEL FINDINGS}

\subsection{PRIMARY CONCLUSIONS}

The reviewers agreed that Raman spectroscopy is an excellent method for the tank waste characterization and screening problems that were presented. These problems are the identification of major molecular constituents for the purpose of screening the waste to determine homogeneity and the presence of key species. They agreed that there is a good chance that the method would be successful as presently envisioned.

The above conclusions were based on the following facts.

- The waste to be characterized is primarily concentrated solutions and solids, which are amenable to characterization by Raman spectroscopy.

- The wastes are optically opaque and highly scattering, ruling out methods that rely on optical transmission through the material.

- Good optical fibers are available that are highly transmissive in the wavelengths, which will be sensed by Raman, making it possible to take the measurements remotely. This is not the case with ultraviolet or infrared optical methods.

- Raman spectroscopy provides the type of information needed for the tank waste screening applications. It will identify major molecular components of the waste and can be used to flag specific components of concern. 
It was noted that many of these points are particularly important in selecting a method that can be used for in situ sensing. The hot cell and laboratory environments are less restrictive so that other methods may be used, but Raman is one of the few methods that could be used in the tanks.

\subsection{SYSTEM DESIGN CONSIDERATIONS}

A number of issues were identified that drive the design of the entire Raman system. They are as follows:
1. Choice of laser wavelength
2. Remote versus local filtering
3. Raman shift range and resolution
4. Time frame until operational use
5. Frequency and ease of calibration
6. Optical configuration.

Because each of these choices has implications for many other aspects of the technology and methods, they need to be considered thoroughly and jointly. In most cases, the reviewers felt that final decisions had not yet been made in the current Raman program and wanted to ensure that all factors were taken into account before making final decisions. In some cases, the reviewers felt strongly about the direction that should be selected.

The reviewers noted that the optimal configuration for Hanford Site tank waste applications may not involve a standard, "off-the-shelf" system. The ideal long-term system configuration may require a special design optimized for this application.

\subsubsection{Choice of Laser Wavelength}

The reviewers recommended using a near-infrared (IR) laser (e.g., 780 nanometers [nm]). This will provide better signal transmission over distances, less radiation-induced attenuation, and less susceptibility to fluorescence. Several impacts on system design were noted.

2.2.1.1 Implications for Detectors. Wavelengths 1onger than $780 \mathrm{~nm}$ put the Raman signals on the upper edge of the charge-coupled device (CCD) detector response. This is especially a problem with materials with large Raman shifts (e.g., ferrocyanide and some organics). Detector quantum efficiency also drops rapidly as wavelength increases. Laser wavelengths longer than $780 \mathrm{~nm}$ (e.g., $830 \mathrm{~nm}$ ) have provided poor results. The 780-nm 1 aser may be a good compromise if issues with stability can be resolved.

2.2.1.2 Filter Choices, Probe Design. Filters will have to be selected based on the laser wavelength. The reviewers did not think that availability of filters at the longer laser wavelengths would be a problem. Semiconductor absorption filters (e.g., CdTe) should be considered, although their behavior in a radiation environment is unknown.

2.2.1.3 Fiber-Optic Transmission. Silica optical fibers transmit well in the near-IR with significantly lower transmission losses than in the $514-\mathrm{nm}$ 
region. This is a major consideration for field applications involving lengths of fiber as great as $900 \mathrm{ft}$.

2.2.1.4 Fiber-optic Darkening. Results presented at the review showed that radiation effects on hydroxide-rich optical fibers were sharply reduced at wavelengths longer then $720 \mathrm{~nm}$. This supports the use of a near-IR laser because less radiation-induced degradation will interfere with signals.

2.2.1.5 Fluorescence. Fluorescence occurs primarily in the ultraviolet and visible regions of the spectrum. The reviewers were concerned that fluorescence with 514.5-nm lasers was very likely, based on their experience with a wide variety of samples. They felt the problem could be minimized with the use of a longer wavelength laser.

2.2.1.6 Laser Stability. Diode lasers have had problems with stability, which is one of the reasons that initial efforts to use a longer wavelength laser in the Hanford program were abandoned. However, laser technology is improving rapidly. External cavity diode lasers that do not mode hop are available, and other options for stable lasers in the $700-$ to $800-\mathrm{nm}$ region should be considered.

\section{Recommendations}

Use a 780-nm or similar wavelength 1aser. Design the rest of the system to optimize the Raman response around this excitation. An alternative may be to develop two complete systems, one with a 514.5-nm laser now in use and one with longer wavelength excitation. For future applications, consider the possibility of using a 1,064-nm laser and looking in the anti-Stokes region with a CCD detector. (This is only a possibility to consider, not an approach that is considered superior.)

\subsubsection{Remote Versus Local Filtering}

Filters need to be as close as possible to the sample end of the optical fiber. This becomes more critical as the length of the fibers connecting the probe to the spectrometer (and the induced silica response) increases. Many of the spectra displayed at the review showed significant residual silica signal despite removal of the silica baseine by subtraction. The probe design presented by the Savannah River Technical Center, based on small dielectric filters near the probe tip, appeared attractive.

Good filtering will bring a greater, more reliable improvement to the signal than good noise removal software. The filtering will reduce reliance on silica signal subtraction, which in turn will reduce the need for high stability of the system in the wavelength response. System stability requirements translate into stringent requirements on temperature and other environmental conditions that may not be feasible for field operation. Minor spectral shifts resulting from changing temperature will only affect the ability to do baseline subtraction, not the ability to identify major species (e.g., nitrate). In addition, because shot noise is proportional to the square root of the total optical signal intensity, for a shot-noise-limited system eliminating the silica signal will reduce the overall shot noise. 
Filtered probes require filters with radiation-stable properties. Additional testing may be needed to identify the desired filters. The reviewers suggested that defense-related programs be reviewed to determine if filters (particularly absorption-based filters) are available with known radiation effects in the required wavelengths.

\section{Recommendations}

It is recommended that filters that will withstand the environment be identified and placed close to the sample end.

\subsubsection{Raman Shift Range and Resolution}

A trade-off must be made to determine the relative importance of spectral range and spectral resolution. The reviewers felt that the current resolution was greater than required for these applications and that sacrificing range for further resolution was not warranted. One wave number per pixel was considered an upper limit on resolution. The reviewers expressed a concern that the current systems were throwing away spectral coverage to achieve a point density significantly greater than was needed. With a 1024 channel detector, $2 \mathrm{~cm}^{-1} /$ pixel would provide $2,000 \mathrm{~cm}^{-1}$ coverage.

\section{Recommendation}

It is recommended that the aim be a resolution of one to two wave numbers per pixel.

\subsubsection{Time Frame Until Operational Use}

It was pointed out that different approaches will be taken for short-term implementation of an operational system and for longer term development of an optimal system. In a context such as the Hanford Site, short-term beneficial use is required, but longer term improvements are also warranted.

The reviewers felt it was necessary to distinguish between what is being done (a) to finalize a design for a first-field system and (b) to develop and optimize a system for long-term use. Rapid development of technology (e.g., lasers and detectors) suggests that continuous improvement will be possible for some time to come. However, a complete system must be compiled and tested, procedures developed, and operators trained to achieve benefit from the technology. This requires a moratorium on further technology updates for that system.

\section{Recommendations}

It is recommended that a plan to specify and implement the first operational system be identified. A separate plan to update and improve the technology for long-term use should al so be identified. Hot cell applications with short (less than $10-\mathrm{m}$ ) fibers will likely precede tank use. 
WHC-EP-0785

\subsubsection{Frequency and Ease of Calibration}

A trade-off must be made between the frequency with which the system must be recalibrated and the stability requirements on the system. For a field system, stability may be hard to achieve. Calibration in the field also presents difficulties.

The reviewers leaned toward more frequent calibrations. They felt that calibration procedures should be designed for easy, regular field performance. Standard reference measurements should be designed into the system operations, preferably testing the entire system (i.e., standard samples at the end of the probe). Less desirable alternatives include standard measurements that use the same system but not the probe and fiber-optics.

The reviewers indicated that frequent calibration would have several advantages for this type of operation. Primary among these were a reduction in the need for extremely high system stability and a higher confidence in the validity of the data. Because the frequency and quality of calibration affects the system stability requirements, the intended method of calibration must be selected before the stability requirements are finalized. The calibration plan will then dictate the allowable fluctuations (e.g., of system temperature) that affect system stability. It is good practice to use a calibration standard that resembles sample composition as much as possible.

\section{Recommendations}

It is recommended that tiic calibration procedures for hot cell and field applications be identified. Focus should be on providing field calibration that can be performed frequently.

\subsubsection{Optical Configuration}

There was some concern expressed that the optical configuration presented by Lawrence Livermore did not make the best use of the available iight. Using 400- $\mu$-diameter fibers (with an inherent F-number of about F2) and $F$-number matching the output to the $F 4$ spectrometer results in an $800-\mu-$ diameter footprint on the slit. Using a 50- $\mu$ slit results in poor recovery of the light footprint (Figure 1). Options to be considered include using smaller diameter fibers $(100$ to $200 \mu)$, remaining with the large fibers, and going to an F-2 or F-1.6 focal length for the spectrometer, or increasing the slit size. Several other spectrometer configurations are currently being evaluated, and many factors (including light recovery and image quality) must be considered in making a final decision.

Some of the issues identified relating to reduction of fiber diameter are as follows:

- Tip beveling becomes much more difficult. It is not clear how difficult it will be to overcome this problem.

- Alignment becomes more difficult. The reviewers agreed that the alignment issues could be solved and the resulting system would perform better. 


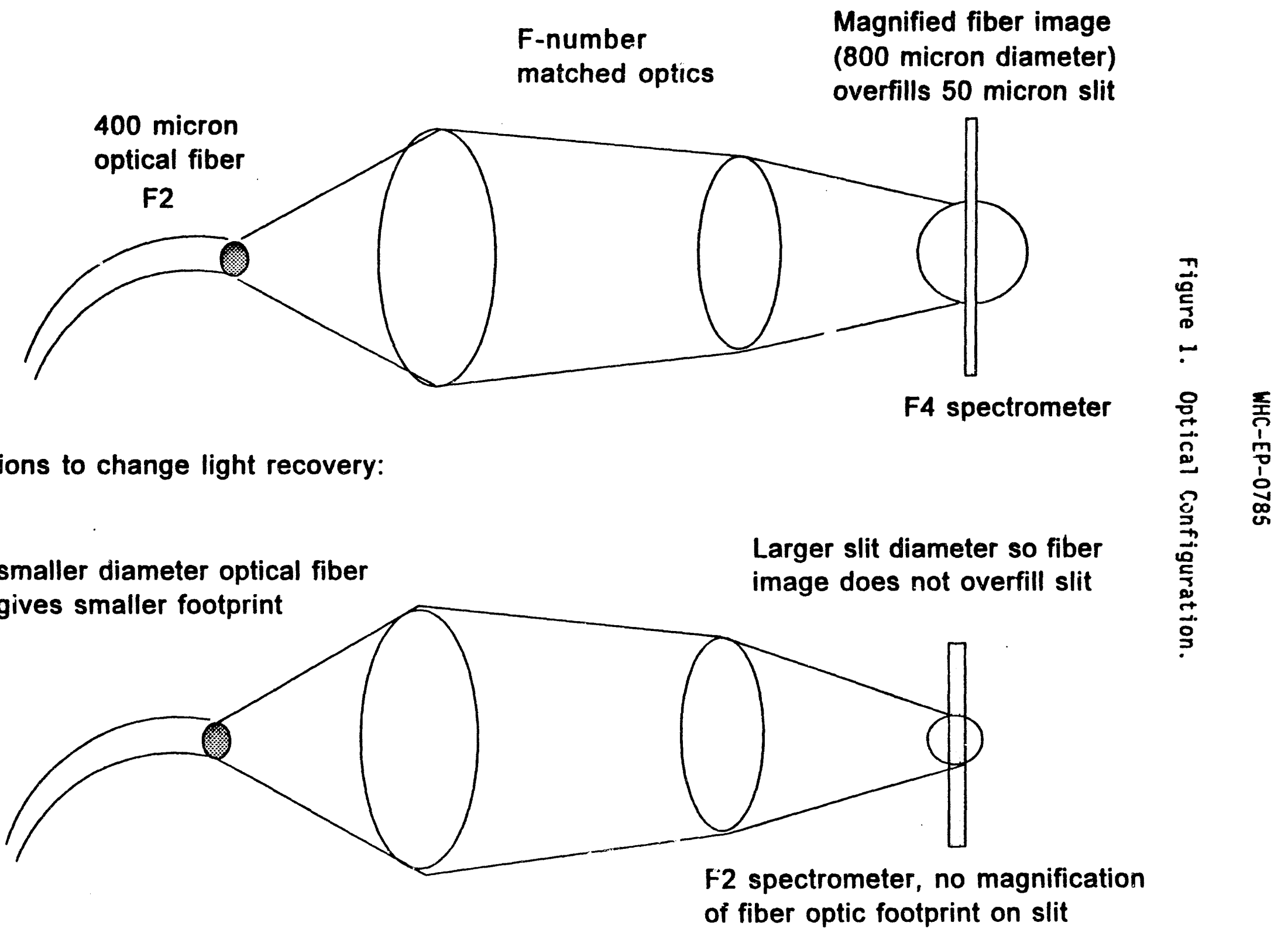


- Sampled area becomes smaller, with a possible effect from the particle size of the samples. The reviewers did not think that a reduction from 400 to $100 \mu$ would cause particle size effects. Currently the particles are believed to be primarily in the micron-size range.

\section{Recommendation}

It is recommended that a complete analysis of the optical configuration be conducted to determine how to achieve the best light recovery and image quality, including comparing fiber size, F-number, and slit configuration.

\subsection{ISSUES}

A number of issues were identified that do not impact system design but that still resulted in recommendations from the reviewers. Following these recommendations may result in better performance of the overall system and program.

\subsubsection{High Technical Risk Areas}

The reviewers identified three areas they considered to be serious threats to a Raman spectroscopy program destined for field operation in a radiation environment. They are as follows:

- Fluorescence

- Radiation damage

- Lack of filtering (when using long fibers).

The issue of fluorescence was addressed in the recommendations for longer wavelength excitation. The studies on radiation damage to optical fibers allay many of the fears in that area, although greater darkening at wavelengths shorter than $720 \mathrm{~nm}$ supports the contention that long wavelength lasers should be used when transmitting over long fibers. Radiation effects on other components of probes still need to be assessed. The filtering was also addressed in Section 2.2.2. If the Raman program takes steps to address each of these technical risk areas, success is highly probable.

\subsubsection{Integration Times}

Integration times reported were higher than the reviewers would have expected. Although some of this may be attributed to the properties of the sample materials, the reviewers felt that it may also be indicative of unusually high losses within the system. Poor alignment was identified as a possible cause. Several of the reviewers volunteered to obtain Raman spectra of surrogate samples on their own systems to compare results. This may be a good way of distinguishing problems stemming from the sample itself from those stemming from the system configuration. 


\subsubsection{Operator Training}

The reviewers indicated that training is needed to recognize what constitutes a good Raman spectrum and what constitutes a poor spectrum. A properly trained operator should be able to recognize immediately certain frequencies that are not Raman-scattering frequencies. The reviewers agreed that additional training for the system operators in the program may be required.

\subsubsection{Hardware Versus Software Corrections}

The reviewers had some concern that there was an overreliance on using software to correct data when the problems could more readily be solved in hardware. In particular, a better result will be obtained if a filtered probe is used to eliminate silica response rather than relying on subtracting silica background after recording the spectrum. This will also reduce the requirement for high instrument stability (Section 2.2.2).

\subsubsection{Detector Noise Sources}

Shot noise associated with a background signal is the limiting factor in the Hanford applications, far outweighing the contributions of detector noise. Liquid nitrogen cooled CCD detectors will never be read-noise limited. Shot noise will be more predominant.

\subsubsection{Software Development Strategy}

There was considerable discussion of the best software development strategy. While some reviewers felt that more use should be made of standard software packages, rather than in-house development, others pointed out that very specialized applications invariably required the development of specialized software. A concern about dependence on in-house software was that documentation is often less complete than with commercial software, and long-term support of the software is not guaranteed. This is particularly an issue when new hardware becomes available.

A suggested strategy is to obtain the best commercially available software and exploit as much of it as possible during the development and testing stages. This approach will allow the developers to identify useful classes of routines. Specialization of routines for Hanford applications is appropriate, but rewriting basic routines that are readily available is discouraged. Because of the need for a highly automated, "turn-key" final system, the developmental software may need to be rewritten in final form by a commercial software supplier. This supplier would provide updates and long-term support.

\subsubsection{Data Analysis and Chemometrics}

Some reviewers expressed concern that the current approach to data analysis relied too heavily on the use of single-peak location. They 
suggested investigating chemometrics to determine whether approaches involving more of the data would yield better results. This advice may be particularly important in field applications where system stabllity cannot be tightly controlled, allowing small shifts in spectral baseline position.

\subsubsection{Quantitative Versus Qualitative Results}

The reviewers were in complete consensus that absolute quantitative measurement will be impossible for tank waste applications. However, they agreed that relative quantitation should be feasible. It should be possible to determine accurately the concentration of one component relative to another, but absolute measurement of the concentration of a single component from its Raman signal is not feasible for tank waste.

\subsection{CONCLUSION}

The review panel concluded that the Raman program should continue, pursuing the general program plan in place now. Specific technical recommendations were made to enhance the probability of success both for short-term hot cell applications and long-term in situ applications. 
WHC-EP-0785

APPENDIX A

AGENDA AND LETTERS OF APPROVAL

A-1 


\section{Raman Spectroscopy Program Peer Review}

Wednesday March 23

FINAL AGENDA

2425 Stevens Drive, Room 208

Richland, WA

8:00 - 8:20 Introduction

Introduction, Welcome, Purpose of Peer Review

Susan Eberlein, WHC

\section{A. Background and Problem Statement}

$8: 20-8: 40$

Environmental Description

Fred Reich, WHC

$8: 40-9: 00$

Chemical Characterization of Hanford Tank Waste

Jim Douglas, WHC

9:00 - 9:20

Technology Selection and Program Plan

Wayne Winkelman, WHC

$9: 20-9: 35$

Raman Fundamentals as Applied to Hanford

Tom Vickers, FSU

9:35 - 10:00 Questions and break

B. Fiber Optic Raman Spectroscopy

10:00 - 10:30

Hot Cell Raman Spectroscopy

Bev Crawford, WHC

$10: 30-10: 50$

Hanford Applications

Fred Reich, WHC

\section{Raman Materials Experience}

$10: 50-11: 10$

Lab Experience (Reference Material)

- Interferences and estimated LUDS

Charlie Mann, FSU

- Pure materials studies

- Early tests with FT Raman vs dispersive Raman

- FSU's phase I and phase II work

$11: 10-11: 30$

Cold Test Experience (Surrogate Samples)

- Simulants

- Homogeneity tests

Tom Vickers, FSU

- Spiking results

WHC-EP-0785

$11: 30-11: 50$

Raman Spectra of Radioactive Samples

Bev Crawford, WHC 


\section{Technologies}

\section{Hardware}

1:00 - 1:20

- Laser

- Spectrometer

- Detector

$1: 20-1: 40$

- Probe design

- Fiber optics

$1: 40-1: 55$

- Radiation testing

Software

$1: 55-2: 25$

- Data acquisition

- Control

$2: 25-2: 55$

- Data analysis

- Data archiving

2:55 - 3:30 Questions and break

E. System Application

\section{$3: 30-3: 50$}

Calibration

$3: 50-4: 20$

Uses of Data

- Quantitative analysis

- Qualitative analysis

$4: 20-4: 40$

Data Validation

$4: 40-5: 00$
Tom Vess, LLNL

Pat O'Rourke, SRTC

Ishwar Aggarwal, NRL

Charlie Mann, FSU

Charlie Mann, FSU

F. Summary, Questions, and Instructions for Panel Reporting 


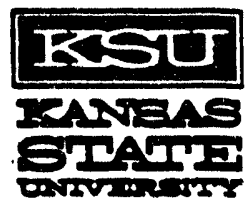

\section{Department of Chemistry}

119 Willard Hall

Manhattan, Kansas 66506-3701

913.532-6865

FAX: 913-532-6866

May 2, 1994

Wayne D. Winkelman

Westinghouse Hanford Co.

P.O. Box 1870, L5-55

Richland, WA 99352

Dear Mr. Winkelman:

I find the Hanford Raman Spectroscopy Program Peer Review report very acceptable.

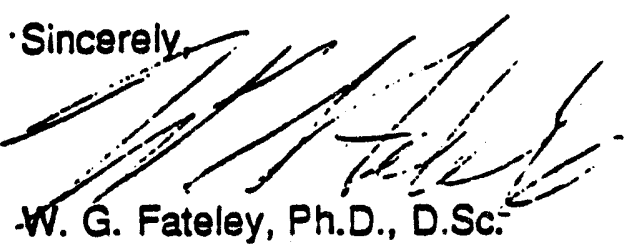

University Distinguished Professor

WGF:Ih 


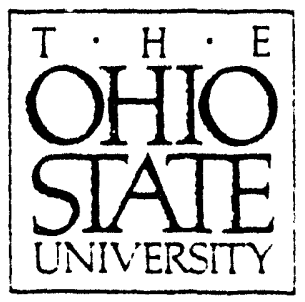

WHC-EP-0785

Department of Chemistry

120 West 18th Avenue

Columbus, $\mathrm{OH}$ 43210-1173

Phone 614-292.2251

FAX 614-292-1685

TELEX 332911

Answer Back Code: OSU CHEM UD

May 2, 1994

Wayne D. Winkelman

Westinghouse Hanford Co.

PO Box 1870, L5-55

Richland WA 99352

Dear Wayne:

I have reviewed the final version of the report on the Hanford Raman Spectroscopy Program Peer Review and believe that is accurately reflects the findings of the review panel. The report summarizes the main findings and recommendations of the panel, and does not overlook any important points.

Although success can never be guaranteed in a research project, I think the approach underway at WHC, combined with the recommendations of the report, is likely to yield a useful analytical probe of hot cell and tank contents.

Sincerely,

$$
\text { Fik me leas }
$$

Richard L. McCreery

Professor of Chemistry

$\mathrm{RLM} / \mathrm{pb}$

enclosure

xc: Susan Eberlein

FAX: 509-376-4661

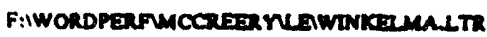




\title{
(2) \\ University of Hawai'i at Mānoa
}

\author{
Hewai't Instlute of Geophysics \\ School of Ocean and Earth Science and Technology \\ 2525 Correa Road - Honolulu. Hawa'l 96822 \\ Tolephone: (808) 956-8760 - Facsimile: (808) 956-3188
}

May 5, 1994

Dr. Wayne Winkelman

Westinghouse Hanford Company

P. O. Box 1870, L5-55

Richland, WA 99352

Ref: Hanford Raman Spectroscopy Program Peer Review Report

Dear Dr. Winkeiman:

As a member of the Peer Review Panel, I have reviewed the final version of the report on the Hanford Raman Spectroscopy program. I believe that the final report accurately reflects the finding of the review panel. The report summarizes the main findings and the recommendations of the panel, and does not overlook any important point.

If I could be of further assistance in this matter, please feel free to contact me by phone (808) 956-8476; by fax (808) 956-8476, or by e-mail sksharma@soest.hawaii.edu.

Sincerely,

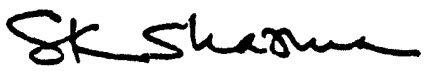

Shiv K. Sharma

SKS/cch 


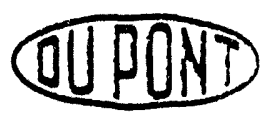

Central Research \& Development

Experimental Station

P.O. Box 80328

Wilmington, Delaware 19880-0328

May 10, 1994

Dr. Wayne D. Winkelman

Westinghouse Hanford Company

P. O. Box 1870, L5-55

Richland, WA 99352

Dear Dr. Winkelman,

I have reviewed the final version of the report on the Hanford Raman Spectroscopy Program Peer Review. In its current form, it accurately reflects the findings of the panel. The major conclusions and recommendations of the panel are related in the report, and no major findings were omitted. If you have any further questions, I can be reached at $302-695-4434$ or $302-655-5819$ (FAX). If you prefer INTERNET, my address is CHASE@ESVAX.DNET.DUPONT.COM

\author{
Sincerely yours, \\ Bruce Chase \\ Bruce Chase
}




\section{DISTRIBUTION}

\section{OFFSITE}

8

Department of Energy-Headquarters 12800 Middlebrook Road

Germantown, MD 20874

Sherry Gibson (3)

Ken Lange (3)

Caroline Purdy

Stan Wolfe

1

Department of Enerqy-Headquarters

Science Applications International Corporation

2030 Century Bivd, Suite 200B

Germantown, MD 20874

Herb Sutter

1

Department of Enerqy-Headquarters

Science Applications International Corporation

555 Quince Orchard Road, Suite 500

Gaithersburg, MD 20878

Steven Wyrick

1

Ames Laboratory

RM 106 Speeding Hall

Iowa State University

Ames, Iowa 50011-3058

Paul Wang

1

EI Dupont Central Research and Development

Experimental Station

PO Box 80328

Wilmington, DE 19880-0328

Bruce Chase

2

Florida State University

Department of Chemistry

Tallahassee, FL 32306-3006

C. K. Mann

Thomas Vickers 
Kansas State University

Chemistry Department

Manhattan, KS 66502-0006

William Fateley

Lawrence Livermore National Laboratory

7000 E. Ave

Livermore, CA 94550

Thomas Vess

Los Alamos National Laboratory

PG Eller

B1-40

1

Mechanical Technologies Incorporated

968 ATbany Shaker Road

Latham, NY 12110

Jim Dill

1

Naval Research Laboratory

4555 Overlook Ave. SW

Washington, DC 20375

Thomas Bilodeou

Code 56032

1

Ohio State University

120 W. 18th Ave

Columbus, $\mathrm{OH} 43210$

Richard McCreery

1

Savannah River Technical Center

773-A, B-156

Aiken, SC 29808

Patrick 0'Rourke

1

University of Hawaii

Department of Geochemistry

2525 Correa Road

Honolulu, HI 96822

Shiv K. Sharma

1

University of Idaho

Chemistry Department

Moscow, ID 83844-2343

Peter Griffiths 
University of South Carolina Columbia, SC 29208

Mike Angel

\section{ONSITE}

Department of EnergyRichland Operations Office

$\begin{array}{ll}\text { Dennis Brown } & \text { K8-50 } \\ \text { John Clark } & \text { R3-72 } \\ \text { Ted Noble } & \text { R3-72 } \\ \text { Debbie Trader } & \text { K8-50 }\end{array}$

31 Westinghouse Hanford Company

$\begin{array}{ll}\text { Dan Acree } & \text { L7-06 } \\ \text { Harry Babad } & \text { R2-78 } \\ \text { Jim Berger } & \text { LO-18 } \\ \text { Bob Cash } & \text { S7-15 } \\ \text { Bev Crawford } & \text { T6-09 } \\ \text { Cherri DeFigh-Price } & \text { R2-31 } \\ \text { David Dodd } & \text { T6-50 } \\ \text { Jim Douglas } & \text { L5-55 } \\ \text { Gary Dukelow } & \text { S7-15 } \\ \text { Susan Eberlein (2) } & \text { S7-31 } \\ \text { Ron Eschenbaum } & \text { N1-21 } \\ \text { Marcus Harris } & \text { L5-55 } \\ \text { Jim Jewett } & \text { T6-09 } \\ \text { Rick Johnson } & L 5-55 \\ \text { Frank Kohlasch } & T 6-09 \\ \text { Tomas Lopez } & \text { L5-55 } \\ \text { Steve Mech } & L 5-55 \\ \text { Bob Popielarczyk } & \text { R } 1-31 \\ \text { Teo Rebagay } & T 6-55 \\ \text { Fred Reich } & L 5-55 \\ \text { Wayne Winkelman (10) } & L 5-55\end{array}$

Pacific Northwest Laboratory

$\begin{array}{ll}\text { William Bonner } & \text { P7-41 } \\ \text { Steve Colson } & \text { K2-14 } \\ \text { Kim Fowler } & \text { K8-19 } \\ \text { John Hartman } & \text { K5-25 } \\ \text { Art Janata } & \text { K2-12 } \\ \text { P. K. Melethil } & \text { P7-22 } \\ \text { Tom Sloane } & \text { K5-25 } \\ \text { Dennis Strachan } & \text { K2-44 }\end{array}$



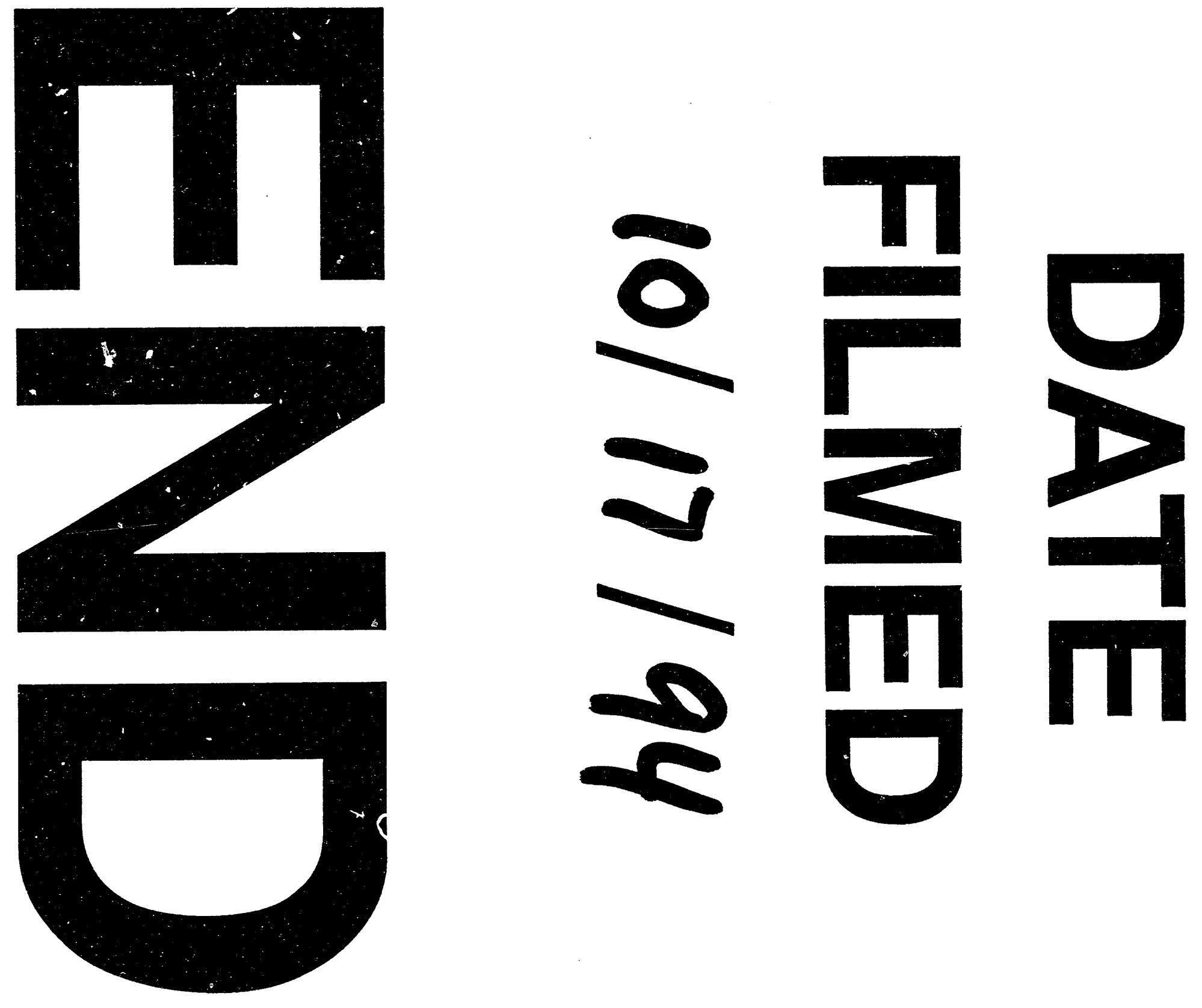
